\title{
Revisitando o passado... (Re)pensando o Presente: o CEFD/UFSM, o Tempo e o Lugar Social do Profissional de Educação Física
}

Revisiting the past ... (Re) thinking the Present: CEFD / UFSM, the Time and the Social Place of the Physical Education Professional

Revisitando el pasado ... (Re) pensando el presente: CEFD / UFSM, el tiempo y el lugar social del profesional de la educación física

Antonio Filipe Pereira CaetanoI, Eriberto José Lessa de Moura ${ }^{\mathrm{II}}$

\section{Resumo}

A obra Memórias das Trajetórias e Desafios no Cinquentenários do Centro de Educação Física e Desporto/Universidade Federal de Santa Maria, organizada por João Francisco Magno Ribas e Maria Cecília da Silva Camargo, publicada este ano pela editora UNIJUI, foi pensada, edificada, escrita e publicada com o propósito de compreender o passado e construir uma visão sobre trajetórias de sujeitos deste Centro. A linha do tempo traçada pela obra descortina uma Unidade Acadêmica plural, diversificada, sólida, consciente de suas ações e, mais do que isso, comprometida com o papel de primeira "Universidade Pública Federal instaurada no interior do país".

Palavras-chave: Memórias do CEFD/UFSM; Formação em Educação física; Programas e projetos; Educação Física

\begin{abstract}
The book Memórias das Trajetórias e Desafios no Cinquentenários do Centro de Educação Física e Desporto/Universidade Federal de Santa Maria, organized by João Francisco Magno Ribas and Maria Cecília da Silva Camargo, published this year by UNIJUI publisher, was designed, built, written and published with the purpose of understanding the past and building a view on the trajectories of subjects in this Physical Educational Center. The timeline drawn by the book reveals a plural, diverse, solid Academic Unit, aware of its actions and, more than that, committed to the role of the first "Federal Public University established in the interior of the country".
\end{abstract}

Keywords: Memories of CEFD / UFSM; Training in Physical Education; Programs and projects; Physical Education

\footnotetext{
I Universidade Federal de Alagoas - UFAL - Endereço : Av. Prof. Manoel Coelho Neto, 29, Apto 203, Jatiúca, Maceió, AL - e-mail: afpereiracaetano@hotmail.com

II Universidade Federal de Alagoas - UFAL - e-mail: marcgfa1@gmail.com
} 


\section{Resumen}

La obra Memórias das Trajetórias e Desafios no Cinquentenários do Centro de Educação Física e Desporto/Universidade Federal de Santa Maria, organizada por João Francisco Magno Ribas y Maria Cecília da Silva Camargo, publicada este año por la editorial UNIJUI, fue diseñada, construida, escrita y publicado con el propósito de comprender el pasado y construir una mirada sobre las trayectorias de los sujetos de este Centro. La línea del tiempo trazada en la obra revela una Unidad Académica plural, diversa, sólida, consciente de su actuación y, más que eso, comprometida con el rol de la primera "Universidad Pública Federal establecida en el interior del país".

Palabras clave: Memorias del CEFD / UFSM; Formación en Educación Física; Programas y proyectos de Educación Física

O tempo é a principal variável do desespero humano! Por suas vicissitudes, particulares, inconstâncias, imprevisibilidade e tanto outros adjetivos, por ora desnecessários de se mencionar, o tempo rouba a vida dos sujeitos, transforma a existência humana e deixa marcas indeléveis na trajetória dos indivíduos. Erico Veríssimo, em O Tempo e o Vento, descreveu a saga mal sucedida dos Terra e Cambará em busca do controle de suas vidas em diversas temporalidades; pretensão invertida de Raul Bopp, poeta modernista, que parou o tempo ao olhar para trás, e relatar memórias de um momento em que o Brasil exalava antropofagia: "você me espere, que depois vou lhe contar uma história".

Cantado em verso e prosa, quem não se lembra da falta de controle temporal mencionado por Lulu Santos - E não há tempo que volte amor, vamos viver tudo que há para viver, vamos nos permitir! -; ou da rapidez/morosidade marcado pelo ponteiro do relógio destacado por Pato $\mathrm{Fu}$ - Tempo, Tempo, mano velho, falta um tanto ainda eu sei, para você correr macio -; ou, da soberania, altivez e domínio de tudo mencionada por Gilberto Gil - Tempo rei, ó tempo rei, ó, tempo rei; transformai as velhas formas do viver; ensinai-me, ó, pai, o que eu ainda não sei; Mãe Senhora do Perpétuo, socorrei. Incontrolável, soberbo e mortal...

... No âmbito da prática do esporte, a mortalidade do tempo atravessa as modalidades, transforma resultados de jogos e ensina ao homem a experimentar sentimentos nunca d'antes imaginados. O tempo da bola de vôlei cair ao chão antes da cortada ou, quem sabe, da grande "ratada" da Scheilla Castro; o milésimo de segundo do Los Angeles Lakers para realizar uma cesta de três pontos e virar uma partida; o sofrido tempo acréscimo no futebol quando o CSA está ganhando o jogo por 2 x 1; ou o tempo desafiado na pista de atletismo por Usain Bolt na corrida de 100 metros rasos (coitado do tempo, Ops!, dos adversários!). O tempo urge... 
No entanto, mesmo diante de todas essas características adversas os historiadores se propuseram enquanto ofício estudar a relação do homem com o tempo, a temporalidade, o impacto deste "ser" nos homens, mulheres, crianças... sujeitos! Marc Bloch, em Apologia a História, escrita em 1949, apontou como se trabalhar o homem no tempo em termos metodológicos, destacando a necessidade de rompimento fulcral com um modelo positivista de narrativa do passado/presente. Em suas recomendações, destacava o homem como centro de sua história, como aquele que conduz o movimento dos fatos; mencionava a necessidade da variabilidade das fontes de informações para construção da análise, que deveriam ser escritas, visuais, orais; apontava a importância da interdisciplinaridade com outras ciências de modo à contribuir para um modelo metodológico próprio; e, por fím, celebrava o ofício como a "arte de compreender e não julgar", um olhar sobre um recorte de tempo, sem a necessidade de construir uma "verdade absoluta".

Nesse espírito de tentar entender a relação homem/tempo, compreender o passado e construir uma visão sobre trajetórias de sujeitos que a obra Memórias das Trajetórias e Desafios no Cinquentenários do Centro de Educação Física e Desporto/Universidade Federal de Santa Maria, organizada por João Francisco Magno Ribas e Maria Cecília da Silva Camargo - foi pensada, edificada, escrita e publicada. O termo "memória" no título demonstra uma certa "melindrosidade" dos autores em não "roubar" o ofício do historiador e não atravessar as fronteiras da ciência, afinal de contas são profissionais de Educação Física escrevendo sobre suas histórias. No entanto, desde Jaques LeGoff, em História e Memória, momento em que se tentou demonstrar o documento como um monumento, que se percebeu os entrelaces, as imbricações e as conexões entre o olhar sobre passado através da memória e o revisitar de outras temporalidades sob o viés da história. Os caminhos podem ser diferentes, mas o destino sempre é mesmo: outro tempo!

Ao longo de toda a narrativa construída, a obra apresenta momentos, questões e personagens que foram fundamentais para a existência do Centro de Educação Física e Desporto. Pode-se elencar, pelo menos, quatro grandes marcos temporais.

O primeiro deles, a própria fundação, totalmente estruturada nos anos 60, subsidiada pelo governo militar para "controlar corpos e não produzir conhecimento" não teve a finalidade esperada de seus governantes, situação que já demonstraria o viés revolucionário dos agentes da história por aquelas bandas. O capítulo desta discussão (Cap. 1 - Linha do Tempo do Centro de Educação Física e Desporto da Universidade Federal de Santa Maria) talvez seja o mais positivista dos outros presentes na obra, com características de marcos temporais, alusão a personagens e feitos, bem como a identificação de datas sequenciais dos acontecimentos. Em história, uma lista de efemérides! Mas não há problema, a ideia era 
mesmo construir essa linha do tempo para si e para outros. Para si, para enxergar os avanços e recuos, bem como celebrar a instituição como a primeira Universidade Federal fora do eixo capital do Brasil; para os outros para servir de espelho, modelo, referência e reportar acima de tudo que o lugar alcançado outrora (mas que se vislumbra para o presente/futuro!) não ficou enraizado na cerimônia da pedra fundamental. O tempo andou e os homens trabalharam... Neste quesito, os dois outros marcos referem-se aos sujeitos da história.

O segundo momento foi a natureza exógena do curso de Educação Física em seu momento pósembrionário, décadas de 70 e 80, personificada com intercâmbios com professores da Alemanha e a possibilidade aos docentes internos de realizarem pós-graduação stricto sensu fora do Brasil. A presença de Jurgen Alfred Friz Dieckert, com o projeto "Esporte para Todos"; Jurgen Koch, com o curso “Arquitetura do Esporte e do Lazer”; Dieter Pepier, com atuação na pós-graduação; Dietmar Kleine, com cursos em Psicologia do Esporte e Aprendizagem Motora; e Reiner Hildebrandt-Stramann atuando na parte pedagógica; alterou profundamente o modus operandi do fazer teórico e pedagógico de alguns docentes da CEFD. Os estrangeirados oportunizaram aos locais uma vivência de esporte diferenciada, não só ligada ao "rendimento" (se é que podemos usar essa terminologia para o período!), mas, principalmente, ao ensinar o esporte para além dos aspectos físicos e motores, mas como um capital cultural.

Neste sentido, em um terceiro momento, tais discussões, influências teóricas e vivências de pesquisa/extensão possibilitaram a construção de abordagens teórica-metodológicas novas para o ensino da Educação Física: a pedagogia crítico-superadora e pedagogia crítico-emancipatória. O papel de professores como Celi Taffarel, Elenor Kunz e Valter Bracht são construídos a partir da fala dos próprios personagens (Cap. 6 - Construção Histórica do CEFD/UFSM em Bracht, Kunz e Taffarel). Aqui utilizouse um método de História Oral de Vida a partir da utilização de um conjunto de perguntas estruturadas para que os sujeitos se enxerguem dentro da História. Enquanto sujeitos e vozes, os personagens podem revisitar experiências, condutas e relações travadas no passado para oportunizar elementos de construção sobre os acontecimentos narrados por outrem.

A História contada pelos próprios sujeitos através de entrevistas teve sua origem em fins dos anos 40 através do projeto de Allan Nevis, nos Estados Unidos, culminando anos depois na construção da Oral History Society, em 1973. De acordo com Meihy, a história oral flerta com elementos da memória, muitas vezes mitigada como uma informação menor, repartida e/ou parcial sobre um acontecimento. No entanto, o viés de história/memória sempre será dado por quem escreve a narrativa, tendo em vista a voz se tornar, ante de tudo, documento, fonte. Essas duas formas de utilização do método de história oral 
podem ser observadas na obra aqui analisada. Se de um lado, no capítulo sobre os professores que fizeram parte do projeto "Coletivo de Autores" a ideia foi demonstrar a trajetória dos personagens que mudaram a metodologia de ensino da Educação Física no Brasil (sobretudo escolar) através de revelações de sua formação, construções de ideia e reconhecimento de seu papel na construção de um determinado lugar (CEFD); por outro lado, o descortinar do livro dá megafone a professora Ingrid Baeker (Cap. 2 - $\mathrm{Na} \mathrm{Voz}$ de Ingrid Marianne Baecker, a História de uma Docente da Educação Física Brasileira) a partir de uma fala sem cortes, free hand (ou free mind, se preferirem!), mas que releva muito de como o CEFD pensou, pensa e pensará! Sim, é memória de uma trajetória de uma professora, mas costurada na história de um lugar! Essa tessitura deixou marcas, tendo em vista a indissociabilidade do pensamento entre ela e “coletivo de autores". É uma memória/história feita no social, no coletivo...

As reverberações desta conjuntura direcionaram para o Programa de Pós-Graduação em Educação e para a Revista Kinesis, o quarto marco destacado (pesquisa) pelos autores na história do CEFD/UFSM. A história da pós-graduação em Educação Física do CEFD ainda que presentes nos capítulos 2 e 6, tem tamanhas fissuras, reflexões e questões para discussão que foram dedicados dois outros capítulos (Cap. 4 - A Trajetória da Pós-Graduação do CEFD/UFSM: Contribuições à Educação Brasileira, Percalços e Desafios; e o Capítulo 7 - Memórias, Vivências e Aprendizados: A Trajetória da Pós-Graduação do CEFD/UFSM na Perspectiva de Professores). Em que pese o objetivo tenha sido apresentar dois lados de uma mesma moeda - sob a luz da documentação e sob a égide das vozes - o discurso foi uníssimo: do auge ao descredenciamento; da reabertura a direcionamentos!

No bojo das contribuições estrangeiras, da condução de pesquisas, de ações de extensões e dos escopos interpretativos/teóricos diferenciados na área do ensino de Educação Física Escolar, o curso de Educação Física do CEFD tornou-se um dos maiores programas de Pós-Graduação do Brasil. No entanto, o importante é destacar que a trajetória foi marcada por inúmeras experiências de programa de especialização (Lato Sensu) em Técnicas Desportivas, Ensino do Movimento Humano e Educação Física Escolar, que precederam o Stricto Sensu e auxiliaram na consolidação de pesquisas e na capacidade do corpo docente em desenvolver trabalhos de formação continuada junto aos seus egressos. O descredenciamento, em 2002, parece ter deixado marcas profundas nos sujeitos que passaram pelo programa, nas vozes que se direcionaram para outros espaços de atuação profissional e naqueles que permaneceram ali e/ou chegaram a posteriori e foram responsáveis pela condução de uma nova versão do programa efetivado em 2012. Aposentadorias, programa de demissão voluntária (PDV) e exonerações de docentes foi relatada como uma das principais razões para este acontecimento. Mas, o embate entre a 
presença da área de humanas e biologia na Educação Física parece ter produzido fissuras reverberadas na pós-graduação.

Pedro Hallal \& Victor Andrade de Melo em um artigo recente destacou a mudança de eixo na produção científica da Educação Física, obliteradas nos anos 90, para o âmbito de esporte e para ciência do movimento. Cenário que também foi apresentado por Marluce Corrêa e Colaboradores ao apontar que grande parte desta mudança de eixo estaria sustentada pelas publicações da Educação Física estarem concentradas na subárea de biodinâmica do movimento e avaliada pela a área 21 da CAPES. O aumento desta natureza de produção tornou-se, então, a referência para os programas de Pós-Graduação, trazendo inúmeras limitações para execução de programas com vieses socioculturais e pedagógicos, naturalmente pensados que deveriam estar na área de Educação. Provavelmente, o momento de crise enfrentado pelo Programa de Pós-Graduação em Educação Física do CEFD/UFSM teve como pano de fundo esta realidade.

Outros dois capítulos que corroboram com esta perspectiva foram aqueles que discutiram o papel da Revista Kinesis para a comunidade científica (Cap. 3 - A Trajetória da Revista Kinesis no CEFD/UFSM: Uma História em Dois Tempos) e o sobre o currículo na formação inicial (Cap. 10 - Relações entre as Ciências Sociais e as Ciências Naturais na Formação em Educação Física do CEFED/UFSM).

Numa perspectiva de análise de documentação escrita, a narrativa sobre a Revista Kinesis revela o papel primordial do periódico enquanto lugar de criticidade dentro da produção científica da Educação Física. Como a maioria das revistas tinham por função dar visibilidade as investigações realizadas endogenamente, mas, com os avanços dos critérios de avaliação da CAPES, a necessidade de ampliar os raios de ação de modo nacional e internacional tornou-se algo latente. Passando pela versão impressa e digital, a revista vivenciou o mesmo break da PPGEF (1976-2002; 2012 até os dias atuais) e foi exatamente pela demanda da Pós-Graduação que o periódico, em 1984, se modernizaria, mudaria de nome e buscava melhores qualificações nas avaliações da CAPES. Uma lacuna neste capítulo, para além dos números e personagens importantes que conduziram a revista, foi a ausência de discussão de artigos importantes da área que foram publicados pela revista e produziram um imenso impacto na comunidade científica. Por outro lado, os apontamentos dos novos direcionamentos afiliaram o periódico ao eixo pedagógico ou sociocultural, transformando-a em uma revista com um escopo específico e extremamente raro no cômputo geral dos periódicos da Educação Física na atualidade.

No que se refere a formação inicial, a partir também de uma pesquisa documental, mas costurada com vozes que vivenciaram a experiência, os autores discutiram as relações de aproximações, distanciamentos e neutralidades entre as ciências naturais e ciências humanas na Educação Física. 
Interessante foi o destaque a fala do Prof. Bracht ao discorrer sobre o assunto: "equívocos mal entendidos". Ao longo dos anos, o curso de Educação Física teve 4 currículos que se assemelham ao natural desenvolvimento de praticamente todos os cursos no Brasil: perfil "esportivista" até os anos 80; inclusão de elementos e avanços nos saberes técnico-pedagógicos nos anos 90; e a fissura entre bacharelado e licenciatura nos anos 2000. O interessante notar que muitas destas mudanças ocorridas nos projetos pedagógicas estavam mais alinhadas aos interesses de pesquisa e atuação profissional docente do que baseada nas necessidades do mercado profissional do egresso.

Este capítulo e todo este debate envolvendo a formação dimensional do profissional de Educação Física proposta pelos autores encontra-se, atualmente, no centro dos debates dos mais variados centros, institutos e departamentos do Brasil, tendo em vista a necessidade de enquadramento dos cursos à Resolução No 6/2018 do Conselho Nacional de Educação. Este direciona os cursos de Educação Física para uma formação de tronco comum com conteúdos básicos das áreas de humanas, biológicas, sociais e nos próprios conteúdos basilares da Educação Física, para sim, em eixos específicos, obterem a formação da habilitação requerida (licenciatura ou bacharelado). Ainda que a proposição tenha atropelado outras propostas que se encontravam em andamento para repensar a área de Educação Física, a Resolução traz um elemento interessante em fazer com que o ingressante vivencie as discussões gerais, básicas e interconectadas entre as possibilidades de formação do profissional para que em um segundo momento opte para onde quer verticalizar sua atuação do mercado de trabalho. No entanto, não restam dúvidas, que, em virtude das discussões emergidas do impacto causado pela pandemia do COVID-19, o eixo saúde perpassará tais currículos, tendo em vista ter se configurado como o principal lugar social que o profissional de Educação Física poderá contribuir significativamente para a sociedade (na escola, nos espaços de lazer, nas redes de atenção básica e, até mesmo nas academias de ginástica).

Justamente este lugar social e suas aproximações junto a comunidade local, regional e nacional que as ações do curso de Educação Física do CEFD/UFSM podem ser vislumbradas em outros capítulos, demonstrando que, para além do "produtivismo" científico, ofertar ações à população faz jus ao papel da Universidade em se aproximar das pessoas que vivem ao torno dela. Formação de equipes de alto rendimento esportivo, ações de extensão, educação inclusiva, atuação em políticas públicas de lazer e desenvolvimento da formação de iniciação à docência. Na presente obra, a construção das narrativas envolvendo essas experiências deu-se por cruzamentos de fontes: documentos oficiais, vozes e memórias vivenciadas, bem como um conteúdo imagético interessante. Neste caso, o olhar sobre o passado foi construído por várias matrizes, mas que no final das contas traçam uma foto viva, pulsante e emblemática para a vida acadêmica para além dos muros da Universidade. 
Em virtude da origem atrelado ao esporte, muitos cursos de Educação Física no Brasil tentaram vocacionar sua atuação para abraçar uma modalidade. Não sei se o handebol escolheu Santa Maria ou se foi o contrário, mas fato é que entre 1969 e 2000 a cidade viveu, respirou e sentiu o desenvolvimento da cultura esportiva na região (Cap. 5 - O Handebol Masculino e o CEFD/UFSM: Protagonismo e Entrecruzamentos). Os autores recuperaram personagens importantes, como Luiz Beno Lang, que os auxiliaram a narrar a transformação da cidade no "epicentro" do handebol. Mas, não se pode deixar escapar a inter-relação feita entre ensino da modalidade e os resultados no alto rendimento. Os passos dados na construção do mini-volei, na preocupação pedagógica no ensino do esporte, na construção de mecanismos de minimizar ansiedades entre pais e filhos, e na elaboração de estratégias para separação entre vitória e desempenho feita ao longo de disciplinas na Universidade, devem ser considerados com influências diretas no momento quando se observa a criação da Associação Desportiva Universitária de Santa Maria (ADUSM) e a transformação da cidade, em 1982, na sede do treinamento de juniores da seleção masculina de handebol. Sem dúvida, foi um momento mágico, provavelmente freado pelos afazeres da Pós-Graduação e das exigências de produção dentro no sistema de pesquisa na Universidade. Fica à memória...

Talvez uma outra ação universitária que reverbere em tamanha intensidade de participação tanto quanto o esporte é a extensão. Neste caso, a obra apresenta um protagonismo latente do curso de Educação Física, bem como a sua responsabilidade social em desenvolver uma promoção da saúde, uma melhora na qualidade de vida e oportunizar experiências da cultura corporal do movimento aos mais vulneráveis (Cap. 8 - Desafios e Contribuições do CEFD/UFSM para o Debate das Políticas Públicas de Esporte e Lazer). Tais ações foram materializadas a partir da influência do modelo norueguês do "Esporte para Todos" cotejadas pelas orientações da ONU/UNESCO, em 1976, que apontava que o esporte deve ser para qualquer ser humano. Esse caminho foi trilhado por outras ações como "Projeto Criança Cidadã", "Programa 20 Tempo Universitário" e "Programa Esporte e Lazer da Cidade" que, com diferentes fontes de financiamento, tiveram como pressupostos a ideia de "emancipação cidadã" e transformação do sujeito empoderado de seu corpo, de sua cultura e suas práticas artísticas. Eram ações integradas entre cultura corporal, artes, educação cidadã e benefícios biopsicossociais. Ainda cabe mencionar que o conjunto das ações de extensão desenvolveu a possibilidade de construção de um Centro de Desenvolvimento de Esporte Recreativo e Lazer na cidade, a partir e em concomitância da elaboração de uma Mapa de Esporte e Lazer no Rio Grande do Sul e da recuperação dos registros de jogos tradicionais e autóctones da América Latina. Logo, o curso de Educação Física já se preocupava com uma das questões mais autuais na área: as barreiras para prática de atividade física para comunidade. Tal perspectiva, materializada em 
suas ações, apontam para uma preocupação em fomentar a cultura corporal do movimento de forma crítica, viável, possível e aderente da população.

A atenção com os mais vulneráveis também pode ser observada na educação inclusiva construída como pauta desde o início dos anos 90 pelos docentes do curso (Cap. 9 - Educação Inclusiva e a Formação Profissional: a Trajetória do CEFD/UFSM e NAEEFA). Neste capítulo, manifestou-se a intenção em demonstrar como as políticas públicas voltadas para a população com deficiência impactou na dinâmica de extensão e pesquisa dos docentes. Inclusão da disciplina “Atividade Física Adaptada” nos projetos pedagógicas (primeiro como complementar e, posteriormente, como obrigatória); desenvolvimento do projeto “Atividades Aquáticas para pessoas com Necessidades Especiais”, a criação do grupo de dança "Extremus" com pessoas em cadeira de rodas e realização de eventos/intercâmbios para discutir a problemática, momento em que se pode detectar, mais uma vez, a influência estrangeira, especialmente com a técnica de Braunschweig. Cabe mencionar que o olhar sobre esta temática foi efetivado pelos docentes tanto por ações de extensão como por formações continuadas, cursos e especializações, de modo que a ampliação do conhecimento pudesse sensibilizar os profissionais de Educação Física para o mercado de trabalho, a comunidade para conviver com pessoas com deficiência e os próprios sujeitos destas análises visando a compreensão do seu corpo, do seu lugar do mundo e como a cultura corporal do movimento pode promover benefícios a sua saúde e bem-estar físico e mental. Ainda que no texto houvesse a apresentação da história no Núcleo Acadêmico de Estudos sobre Educação Física Adaptada (NAEEFA), bem como sua vocação externa, fomentou-se um pouco mais de curiosidade de como a atuação se dava para as pessoas com deficiência matriculadas na Universidade e como o Núcleo desenvolvia ações para melhor as condições de estudo, acessibilidade e outras práticas acadêmicas que incluíam essas pessoas no cotidiano universitário.

Por fim, nos foi apresentada a aproximação dos alunos na graduação em Licenciatura com o mercado profissional através do Programa de Iniciação à Docência (Cap. 11 - O PIBID como Política Pública de Educação: Contribuição do Subprojeto Educação Física do CEFD/UFSM ao longo dos Anos). A implementação do PIBID nos cursos de Licenciatura nas Universidade Públicas do Brasil teve por objetivo promover melhorias na Educação Básica através da aproximação entre Universidade Pública e as Escolas para além do Estágio Supervisionado. O interessante do programa é abreviação da atuação profissional tendo em vista a natureza de imersão do programa que promove ao discente a participação em todas as etapas do processo de ensino-aprendizagem. O CEFD iniciou a adesão ao programa em 2009 a partir do viés "cultura esportiva na escola", proporcionando aos graduandos uma valorização do tempo do estágio supervisionado e destacando a importância do planejamento da Educação Física Escolar. Os 
benefícios angariados com o projeto levaram a inclusão, em 2018, do Programa Residência Pedagógica, outra imersão institucionalizada em espaços públicos de Ensino-Aprendizagem. Logo, com a inclusão da história destes dois programas dentro do curso, a obra reafirma a preocupação e o papel vanguardista do CEFD/UFSM na Educação Física Escolar e com a temática das ciências humanas e sociais na prática do profissional da Educação Física.

Graduação, pós-graduação, pesquisa, extensão, esporte de alto rendimento, formação à docência, política inclusiva, revista científica... A linha do tempo traçada pela obra descortina uma Unidade Acadêmica plural, diversificada, sólida, consciente de suas ações e, mais do isso, comprometida com o papel de primeira "Universidade Pública Federal instaurada no interior do país", repetida tantas vezes no texto.

Ciro Flamarion Cardoso e Ronaldo Vainfas, em Domínios da História, apresentaram ao pesquisador caminhos possíveis para aqueles que visavam se enveredar pelo ofício do historiador. Ainda aquela obra tenha sido escrita, a princípio, aos historiadores em formação e atuação, os autores expuseram inúmeras teorias e metodologias possíveis para se olhar o passado que poderiam (e podem) ser utilizadas por quaisquer sujeitos que tenham como objetivo se enveredar pela ciência do homem no tempo. Se levarmos em consideração que até a publicação da Lei No 14.038, de 17 de agosto de 2020, que regulamenta a profissão de Historiador (que por incrível que pareça não existe enquanto profissão!), qualquer pessoa poderia (e deveria) pensar, narrar e escrever sobre sua história, de sua comunidade e do local, a história escrita pelos professores do CEFD honraram a profissão.

A "história vista de baixo", construída por grande parte da obra de E.P. Thompson, foi efetivada por Ribas e Camargo ao ouvir professores, ex-professores, discentes e aqueles que se fizeram presentes nos corredores, projetos e ações do CEFD. Enfim, ofertar o protagonismo das informações aos sujeitos daquele tempo. Por conta do uso e abuso das fontes orais, bem como pela imensa triangulação e/ou quadriangulação dos documentos históricos, as páginas desta obra deixariam felizes Carla Bassanezi Pinsky, Carlos Bacellar e outros autores que, embrenhados no espírito da Escola dos Annales, defendiam que uma História só pode ser contada a partir de muitas informações (fontes) tendo em vista que cada documento apresenta uma visão, um olhar para os fatos. E seguindo as diretrizes de Carlo Ginzburgo, em Mitos, Emblemas e Sinais, seguiram as pistas, os rastros e os caminhos deixados pelos sujeitos da Educação Física e olharam para dentro, para fora, para todos os lados, para (re)conhecer o passado e analisar os reflexos destes acontecimentos nas embrenhadas situações do presente.

Logicamente que toda ação produtiva desta natureza tem o viés de comemoração. Desvelar memórias é, antes de tudo, comemorar, ver como foi bom, o que foi feito até então... mas, serve inclusive 
para reconsiderações, avaliações críticas, apontar os erros estratégicos e observar experiências bem sucedidas. O olhar crítico dos autores aqui analisados direciona para o principal viés de uma narrativa histórica: olhar distante, influenciado pelo tempo presente e com uma observação analítica. Dói! O que podemos mudar? O que conseguiremos mudar? Como iremos fazer estas mudanças? Sem dúvida, a perda do lugar e reconhecimento de ser um dos principais cursos de Educação Física de referência no Brasil deixou cicatrizes profundas, marcas reveladas nas tintas dos papéis apresentados ao leitor em formato de coletânea comemorativa. Mas, o que vale a excelência se o legado não existe? E nesse sentido, o CEFD deixou muitas cicatrizes, talvez, a principal delas é consciência na formação de profissionais que percebam que o ofício da Educação Física se constitui em fazer do sujeito consciente do seu eu no corpo! Ou seja, que a "societização" passa pela cultura corporal do movimento e que através deste movimento sujeitos conscientes, críticos, com qualidade de vida, bem-estar e atinentes ao seu papel de transformar a sociedade se efetive. Acho que o sonho da Profa. Ingrid Baecker se realizou e ela nem sabe!

Mas, algumas lacunas foram percebidas. Ainda que localizada no centro do Estado, as relações de Santa Maria com as fronteiras nacionais foram pouco cotejadas. Não se sabe se é uma característica do curso de Educação Física, da Universidade ou da própria cidade. Outra fronteira ausente, mas interna, é a do Movimento Estudantil. Os discentes foram trazidos à luz enquanto personagens bem sucedidos da formação acadêmica, mas não visitados enquanto agentes políticos nos corredores do CEFD/UFSM. O lugar, o papel e a atuação do Centro Acadêmico de Educação Física não emergiu na narrativa. Silêncio!

A obra de Ribas e Camargo nos trouxe um tempo acadêmico, da Universidade, de outrora, mas guiado para andar para frente, pois os autores têm consciência de que o tempo não parará e novos alunos, projetos, participantes e personagens virão... Neste caso, nada melhor do que fazer a oração ao tempo, nos ensinada por Caetano Veloso, para dizer - És um senhor tão bonito; quanto a cara do meu filho; tempo, tempo, tempo, tempo, vou te fazer um pedido; tempo, tempo, tempo, tempo - permita que mais experiências, vivências e oportunidades sejam oportunizadas por esses personagens para que no futuro, em um novo olhar para atrás, a sensação de satisfação seja tão presente quanto neste momento.

\section{Referências}

BLOCH, Marc. Apologia à História ou o Ofício do Historiador. Rio de Janeiro: Zahar, 2001.

CARDOSO, Ciro Flamarion S. \& VAINFAS, Ronaldo. Domínios da História - Ensaios de Teoria e Metodologia. São Paulo: Campus, 1997. 
CORRÊA, Marluce Raquel Decian; CORRÊA, Leandro Quadro; RIGO, Luíz Carlos. A Pós-Graduação na Educação Física Brasileira: Condições e Possibilidades das Subáreas Sociocultural e Pedagógica. Revista Brasileira de Ciências do Esporte, 2019; 41(4): 359-366.

FERREIRA, Janaína Amado Marieta de Moraes. Usos e Abusos da História Oral. São Paulo: Editora FGV, 2015.

GINZBURGO, Carlo. Mitos, Emblemas e Sinais: Morfologia e História. São Paulo: Companhia da Letras, 1989.

HALLAL, Pedro C. \& MELO, Victor Andrade de. Crescendo e Enfraquecendo: Um Olhar sobre os Rumos da Educação Física no Brasil. Revista Brasileira de Ciências do Esporte. 2017; 39(3): 322:327.

LE GOFF, Jacques. História e Memória. Campinas: Editora da Unicamp, 2003.

MEIHY, José Carlos Sebe Bom. Manual de História Oral. São Paulo: Loyola, 1996.

PINSKY, Carla Bassanezi (ORG) Fontes Históricas. São Paulo: Contexto, 2008.

THOMPSON, E.P. A História Vista de Baixo. São Paulo: Unicamp, 2001.

\section{Como citar este artigo}

CAETANO, A. F. P.; MOURA, E. J. L. Revisitando o passado... (Re)pensando o Presente: o CEFD/UFSM, o Tempo e o Lugar Social do Profissional de Educação Física. Revista Kinesis, santa Maria, Dossiê CEFD 50 anos, p.01-12, 2020.

*O presente trabalho não contou com apoio financeiro de nenhuma natureza para sua realização. 